\title{
The impact of global warming on the Southern Oscillation Index
}

\author{
Scott B. Power • Greg Kociuba
}

Received: 11 February 2010/Accepted: 23 November 2010/Published online: 10 December 2010

(C) The Author(s) 2010. This article is published with open access at Springerlink.com

\begin{abstract}
The Southern Oscillation Index (SOI) - a measure of air pressure difference across the Pacific Ocean, from Tahiti in the south-east to Darwin in the west-is one of the world's most important climatic indices. The SOI is used to track and predict changes in both the El NiñoSouthern Oscillation phenomenon, and the Walker Circulation (WC). During El Niño, for example, the WC weakens and the SOI tends to be negative. Climatic variations linked to changes in the WC have a profound influence on climate, ecosystems, agriculture, and societies in many parts of the world. Previous research has shown that (1) the WC and the SOI weakened in recent decades and that (2) the WC in climate models tends to weaken in response to elevated atmospheric greenhouse gas concentrations. Here we examine changes in the SOI and air pressure across the Pacific in the observations and in numerous WCRP/CMIP3 climate model integrations for both the 20th and 21st centuries. The difference in meansea level air pressure (MSLP) between the eastern and western equatorial Pacific tends to weaken during the 21st century, consistent with previous research. Here we show that this primarily arises because of an increase in MSLP in the west Pacific and not a decline in the east. We also show, in stark contrast to expectations, that the SOI actually tends to increase during the 21 st century, not decrease. Under global warming MSLP tends to increase at both Darwin and Tahiti, but tends to rise more at Tahiti than at Darwin. Tahiti lies in an extensive region where MSLP tends to rise in response to global warming. So while the SOI is an excellent indicator of interannual variability in
\end{abstract}

S. B. Power $(\square) \cdot$ G. Kociuba

Centre for Australian Weather and Climate Research,

Bureau of Meteorology, GPO Box 1289, Melbourne, Australia

e-mail: s.power@bom.gov.au both the equatorial MSLP gradient and the WC, it is a highly misleading indicator of long-term equatorial changes linked to global warming. Our results also indicate that the observed decline in the SOI in recent decades has been driven by natural, internally generated variability. The externally forced signal in the June-December SOI during 2010 is estimated to be approximately $5 \%$ of the standard deviation of variability in the SOI during the 20th century. This figure is projected to increase to $40 \%$ by the end of the 21 st century under the A2 SRES scenario. The 2010 global warming signal is already a major contributor to interdecadal variability in the SOI, equal to $45 \%$ of the standard deviation of 30-year running averages of the SOI. This figure is projected to increase to nearly $340 \%$ by the end of the 21st century. Implications that these discoveries have for understanding recent climatic change and for seasonal prediction are discussed.

Keywords Global warming - Southern Oscillation Index $\cdot$ Seasonal prediction $\cdot$ Climate change

\section{Introduction}

The Southern Oscillation Index (SOI) is one of the world's most important climatic indices. The SOI is a measure of the difference in mean sea level (air) pressure (MSLP) between Tahiti $\left(17^{\circ} 31^{\prime} \mathrm{S}, 210^{\circ} 26^{\prime} \mathrm{E}\right)$ in the south-eastern Pacific and Darwin $\left(12^{\circ} 28^{\prime} \mathrm{S}, 130^{\circ} 50^{\prime} \mathrm{E}\right)$ in northern Australia to the west of the Pacific Ocean. It is used to track and predict changes in the strength of the Walker Circulation (WC) - one of the worlds most prominent and important atmospheric wind systems. The WC extends across the entire tropical Pacific Ocean, encompassing (1) the trade winds blowing from east to west, (2) air forced to 
rise over the western Pacific, south-east Asia and northern Australia through enhanced convection, (3) winds blowing counter to the trades aloft, and (4) air descending over the eastern Pacific Ocean (see e.g. Gill 1982).

Changes in the WC are strongly linked to the El NiñoSouthern Oscillation (ENSO) phenomenon, which drives major changes in rainfall (Ropelewski and Halpert 1989; Allan et al. 1996; Power et al. 1999), river flow (Kahya and Dracup 1993; Merendo 1995; Power et al. 1999), agricultural production (Phillips et al. 1998; Hammer et al. 2000; Power et al. 1999), ecosystems (Holmgren et al. 2001) and disease (Nicholls 1993; Bouma and Dye 1997; Pascual et al. 2000) in many parts of the world. ENSO can be regarded, in broad terms, as an irregular vacillation between two opposite phases: El Niño and La Niña. The WC weakens during El Niño years and strengthens during La Niña (e.g. Philander 1990). The SOI tends to be negative during El Niño and positive during La Niña. It is used to predict e.g. rainfall, tropical cyclone land-falls, streamflow, agricultural production, fish stocks, fire frequency and the spread of disease (e.g. Walker 1923, 1924; Shukla and Paolino 1983; Swetnam and Betancourt 1990; Nicholls 1993; Aidiku and Stone 1995; Stone et al. 1996; Eltahir 1996; Lehodey et al. 1997; Ward 1998; Chiew et al. 1998; Maelzer et al. 1999; Power et al. 1999; Linthicum et al. 1999; Pascual et al. 2000; Chu and He 1994; Callaghan and Power 2010). It is therefore of wide interest and high importance to know if the SOI is affected by global warming and what the implications of any influence might be for prediction.

The WC weakened during the 20th century and the early 21 st century (Tanaka et al. 2004; Vecchi et al. 2006; Meehl et al. 2007a; Power and Smith 2007; Collins et al. 2009; Vecchi et al. 2006). In fact the dominance of El Niño and the weakening of the WC measured using the SOI reached record levels in 1977-2006 (Power and Smith 2007). This weakening is thought to be partly due to global warming (Vecchi et al. 2006; Power and Smith 2007; Vecchi et al. 2006; Collins et al. 2009) and partly due to both a natural increase in the frequency of El Niño and a natural reduction in the frequency of La Niña (Trenberth and Hoar 1997; Folland et al. 2001; Power and Smith 2007). While Power and Smith (2007) discussed the possibility that global warming might be partially responsible for the observed decline in the value of the SOI after 1976, they pointed out that further research was needed to help quantify the extent to which global warming had in fact driven the post-1976 decline in the SOI. The primary purpose of the research described in this paper it to test the hypothesis that global warming drives a decline in the SOI and to quantify the magnitude of any change. We will also re-examine the extent to which the SOI provides a reliable indicator of changes in the WC. We do this using both observations and results from the WCRP/CMIP3 data base of climate models for the 20th and 21 st centuries.

The SOI, other related indices, and the climate model data base used in this investigation are described in the following section. Results are then presented, summarized and discussed.

\section{Methods}

\subsection{The SOI, the "BoxSOI" and other indices}

The formulation for the monthly SOI used here is sometimes called the Troup SOI (Troup 1965) formulation and is given by:

$\mathrm{SOI}=10(\mathrm{~T}-\mathrm{D}-\overline{\mathbf{T}-\mathbf{D}}) / \boldsymbol{\sigma}_{\mathrm{T}-\mathrm{D}}$,

where $\mathrm{T}=$ monthly MSLP at Tahiti, $\mathrm{D}=$ monthly MSLP at Darwin, $\overline{\mathbf{T}-\mathbf{D}}$ is the long-term average of $\mathrm{T}-\mathrm{D}$ for the calendar month, and $\boldsymbol{\sigma}_{\mathrm{T}-\mathrm{D}}$ is the standard deviation of $\mathrm{T}-\mathrm{D}$ for the same calendar month. This formulation is used for the observations and the models. We follow the Bureau of Meteorology convention and use 1933-1992 as the reference period for the calculation of both $\overline{\mathbf{T}-\mathbf{D}}$ and $\sigma_{\mathrm{T}}-\mathrm{D}$.

An analogous formulation is used here to define a "BoxSOI" in which MSLP averaged over eastern and western equatorial boxes replace $\mathrm{T}$ and $\mathrm{D}$ in the above formulation. The regions used are the same as those used by Vecchi et al. (2006): a western box $\left(5^{\circ} \mathrm{S}-5^{\circ} \mathrm{N}, 80^{\circ} \mathrm{E}-\right.$ $\left.160^{\circ} \mathrm{E}\right)$ and an eastern box $\left(5^{\circ} \mathrm{S}-5^{\circ} \mathrm{N}, 200^{\circ} \mathrm{E}-280^{\circ} \mathrm{E}\right)$, which we will refer to as BoxW and BoxE, respectively. The arithmetic differences $\Delta \mathrm{P}=\mathrm{T}-\mathrm{D}$ and $\operatorname{Box} \Delta \mathrm{P}=$ BoxE - BoxW will also be examined.

The SOI and Box $\Delta \mathrm{P}$ have both been used previously to track changes in the WC (see e.g. Vecchi et al. 2006; Power and Smith 2007). We will examine changes in both to determine if there are any major differences in their behaviour. Changes in the other six indices are also calculated to understand differences in the changes to the SOI and $\operatorname{Box} \Delta \mathrm{P}$ that arise. The observational data for the Box indices is derived from the GPSLP data set from the UK Meteorological Office (Allan and Ansell 2006).

\subsection{Climate models}

We analyse both 20th and 21st century integrations from numerous different coupled general circulation models (CGCMs) available from the WCRP/CLIVAR/WGCM Coupled Model Intercomparison Project (CMIP3, Meehl et al. 2007b). Both the A1B and the A2 SRES scenarios for the 21 st century are analysed. 
Note that not all of the models in the CMIP3 data base used to produce 20th century simulations were used to do A2 runs, and some models were used to do A2 runs but were not used to do 20th Century runs. Multiple runs were conducted using some of the models. Here we analysed 71 model runs from 23 different models for the 20th century. A small number of additional runs were available but we identified technical problems with the archived data and so they are not included in our analysis. Note that the calculation of the SOI in the 21 st century requires runs for both the 20th and 21st centuries (see formulation above). This restricts our analysis of 21 st century variables and changes under the A2 scenario to 34 runs from 17 different models and 52 runs from 21 different models under the A1B scenario.

\section{Results}

\subsection{The observations}

In this section we will describe variability, changes and inter-relationships between the eight key variables, i.e. MSLP at (1) Darwin and (2) Tahiti; (3) the difference, $\Delta \mathrm{P}=$ Tahiti-Darwin; (4) the SOI; (5) BoxW; (6) BoxE; (7) the equatorial pressure difference, $\operatorname{Box} \Delta \mathrm{P}=\mathrm{BoxE}-$ BoxW; and (8) the equatorial BoxSOI. In this note we follow Power and Smith (2007) and restrict attention to June-December.

Note that while the SOI includes a scaling quantity that varies from month to month (i.e. $\sigma_{\mathrm{T}}-\mathrm{D}$ ), $\Delta \mathrm{P}$ does not. The seasonal values of the SOI are averages across the months and represent linear combinations of the monthly $\Delta \mathrm{P}$ values. The formula for the seasonal value of the SOI is therefore not, in general, simply proportional to the seasonal value of $\Delta \mathrm{P}$. Hence it is worth considering variability and changes in both the SOI and $\Delta \mathrm{P}$. While this difference exists, we will show that they behave very similarly. Identical statements apply to the BoxSOI and Box $\Delta \mathrm{P}$.

The correlation coefficients between the eight variables are presented in Table 1 . As expected there is very robust coherence between observed variability evident in the equatorial Pacific (i.e. the Box indices) with both Tahiti and Darwin MSLP. All of the correlation coefficients are statistically significant at the $99 \%$ level (using test described by Power et al. (1998), which takes auto-correlation into account). The link between Darwin and BoxW $(r=0.85)$ is somewhat stronger than the link between Tahiti and BoxE $(r=0.65)$. The SOI and the BoxSOI are also closely related $(r=0.83)$. The relationship between (1) the SOI and $\Delta \mathrm{P}$ and the relationship between (2) the BoxSOI and the Box $\Delta \mathrm{P}$ are both extremely close $(r=1.00$ in both cases).
Table 1 Observations: correlation coefficients between the eight MSLP indices

\begin{tabular}{|l|l|l|l|l|l|l|l|l|}
\hline INDEX & Darwin & Tahiti & $\Delta \mathrm{P}$ & SOI & BoxW & BoxE & Box $\Delta \mathrm{P}$ & BoxSOI \\
\hline Darwin & 1.00 & -0.56 & -0.90 & -0.90 & 0.85 & -0.70 & -0.84 & -0.85 \\
\hline Tahiti & & 1.00 & 0.87 & 0.87 & -0.49 & 0.65 & 0.62 & 0.61 \\
\hline$\Delta \mathrm{P}$ & & & 1.00 & 1.00 & -0.77 & 0.77 & 0.84 & 0.83 \\
\hline SOI & & & & 1.00 & -0.77 & 0.77 & 0.83 & 0.83 \\
\hline BoxW & & & & & 1.00 & -0.70 & -0.93 & -0.93 \\
\hline BoxE & & & & & & 1.00 & 0.92 & 0.91 \\
\hline Box $\triangle P$ & & & & & & & 1.00 & 1.00 \\
\hline BoxSOI & & & & & & & & 1.00 \\
\hline
\end{tabular}

Correlation coefficients between MSLP at Darwin, Tahiti, $\Delta \mathrm{P}=$ Tahiti - Darwin, the SOI, MSLP in the two equatorial boxes BoxW and BoxE, the equatorial pressure difference, Box $\Delta \mathrm{P}=$ BoxW - BoxE, and the equatorial BoxSOI. All correlation coefficients are calculated over the period 1876-1999 using June-December average values of each variable. All correlation coefficients are statistically significant at the $99 \%$ level. Row and column involving the SOI shaded to facilitate reading only. The high level of statistical significance of the correlation coefficients between a given index and one of the time series used to construct that index (e.g. between the SOI and Tahiti MSLP) is of course very unsurprising

The variability is comprised of interannual and longerterm variability. To see if the inter-relationships hold on both interannual and longer time-scales the data were smoothed by applying an 11 year running average to all eight indices. This low frequency variability was subtracted from the original data and the correlation coefficients were re-calculated. The resulting correlation coefficients are very similar in magnitude to those presented in Table 1 (not shown). This indicates that the links between the Boxbased indices and the Darwin and Tahiti based indices are strong on interannual time-scales.

However, nearly all of the correlation coefficients between the Tahiti/Darwin-based indices and their Boxbased counterparts increased somewhat in magnitude, suggesting that these links are weaker on longer timescales. This is confirmed in Table 2, which shows the correlation coefficients between the low frequency components of the indices. The links between the Darwin/ Tahiti-based indices remain strong and the links between the Box-based indices remains strong. However, the interrelationship between the Tahiti/Darwin-based indices and their Box-based counterparts are, without exception, weakened. The sign of the correlation coefficients is preserved but the magnitude of the correlation coefficients is reduced.

If this weakening is genuine and not merely a reflection of accumulated observational error, it suggests that the 
Table 2 Observations: correlation coefficients between the low frequency component of the eight MSLP indices

\begin{tabular}{|l|l|l|l|l|l|l|l|l|}
\hline INDEX & Darwin & Tahiti & $\Delta \mathrm{P}$ & SOI & BoxW & BoxE & Box $\Delta \mathrm{P}$ & BoxSOI \\
\hline Darwin & 1.00 & -0.56 & -0.94 & -0.94 & 0.57 & -0.38 & -0.53 & -0.53 \\
\hline Tahiti & & 1.00 & 0.82 & 0.81 & -0.33 & 0.31 & 0.35 & 0.35 \\
\hline$\Delta \mathrm{P}$ & & & 1.00 & 1.00 & -0.52 & 0.38 & 0.51 & 0.50 \\
\hline SOI & & & & 1.00 & -0.52 & 0.39 & 0.51 & 0.51 \\
\hline BoxW & & & & & 1.00 & -0.60 & -0.90 & -0.90 \\
\hline BoxE & & & & & & 1.00 & 0.89 & 0.89 \\
\hline Box $\Delta P$ & & & & & & & 1.00 & 1.00 \\
\hline BoxSOI & & & & & & & & 1.00 \\
\hline
\end{tabular}

An 11-year running average was applied to the eight indices before calculating the correlation coefficients. All correlation coefficients are calculated over the period 1881-1994 using June-December average values of each variable. Row and column involving the SOI shaded to facilitate reading only

spatial character of the variability is somewhat different on longer time-scales.

Trends in the Darwin- and Tahiti-based indices were also calculated for the three periods: 1876-2008, 1900-2008 and 1958-2008, to see how robust the trends are. The results are presented in Fig. 1a. The choice of 1958 as one of the start-dates is included because it coincides with the start-date used by Nicholls (2008) in his recent analysis of trends in the observed SOI. The sign of the changes for the various periods are all the same apart from the small (inconsistent) changes at Tahiti. MSLP at Darwin increased, both $\Delta \mathrm{P}$ and the SOI declined. None of the trends are statistically significant at the $95 \%$ level. The trend in Darwin MSLP over the longer period is significant at the $90 \%$ level and over the 20th century at only the $85 \%$ level. Statistical significance and the $t$ statistics were assessed using the method described by Power et al. (1998) using the year as one of the time series.

Trends in the four Box indices were calculated for three periods: 1876-1999, 1900-1999 and 1958-1999. The results are presented in Fig. 1b. The sign of the trend and changes in the box-based indices are the same for the three periods considered. Trends for BoxE, Box $\Delta \mathrm{P}$, and the BoxSOI are all negative, while the trends at BoxW are all positive. The trends are statistically significant (near or above the 95\% level) in all four box-based indices for the two longer periods. The trends since 1958 have the same sign as the trends in the longer periods, but are smaller in magnitude and are generally only statistically significant at low levels. The exception to this is the positive trend in BoxW, which is significant at the $95 \%$ level. We will compare observed trends with modelled trends below.

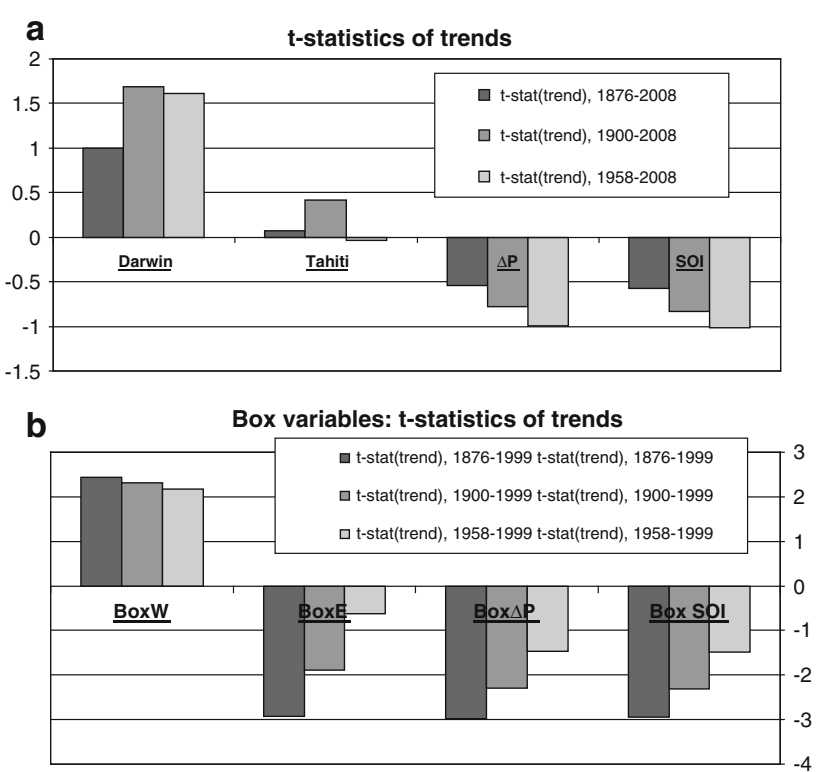

Fig. 1 The $t$ statistics of the observed trends in a the Darwin- and Tahiti-based indices for three periods: 1876-2008, 1900-2008 and 1958-2008 and b the four Box indices for three periods: 1876-1999, 1900-1999 and 1958-1999. Statistical significance was assessed using the method described by Power et al. (1999) using the year as one of the time series. This method takes auto-correlation of both time-series into account

\subsection{Models}

We will begin by examining trends from the model runs under the 21st century A2 scenario because they are largest and easiest to detect. We will then examine trends under the A1B scenario before examining the much weaker trends in the 20th century runs.

Trends under the A2 scenario are presented in Fig. 2, with trends for the box-based indices in Fig. 2a and the Tahiti- and Darwin-based indices in Fig. 2b. Figure 2a indicates that there is a strong consensus amongst the models for the trend in BoxW to be positive, with positive trends in 29 of the 34 runs. The multi-model multi-run mean trend (MMMRM trend, i.e. the average trend across all model runs equally weighted, indicated by the dashed yellow horizontal line in each plot) is $0.4 \mathrm{~Pa} /$ year. There is also a very strong consensus for a negative trend in the BoxSOI (MMMRM trend $=-0.045$ BoxSOI units/year, 30 out of 34 ) and in the $\operatorname{Box} \Delta \mathrm{P}$ (29 out of 34 runs, MMMRM trend $=-0.4 \mathrm{~Pa} /$ year). There is no consensus amongst the models on the sign of the trend in BoxE.

In Fig. $2 b$ we see that there is also a consensus amongst the models for the trend at Darwin to be positive $(0.4 \mathrm{~Pa} /$ year, 25 out of 34$)$ and in MSLP at Tahiti $(0.85 \mathrm{~Pa} /$ year, 32 out of 34 runs). These figures correspond to changes of 40 and $85 \mathrm{~Pa}$ over the century. These changes are small compared with climatological average MSLP at Darwin 

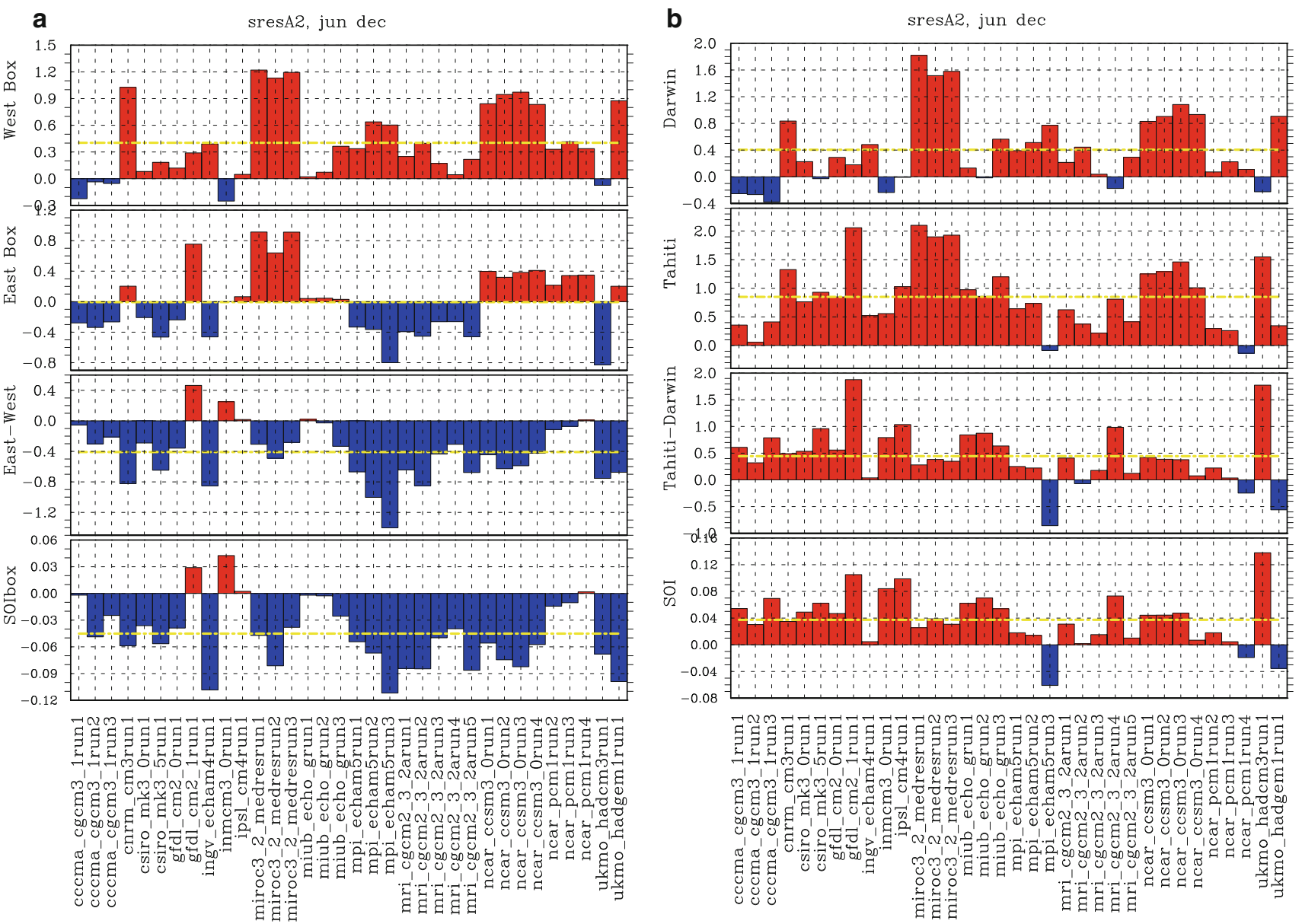

Fig. 2 Modelled 21st century trends in a box-based indices and $\mathbf{b}$ the Tahiti-Darwin based indices under the A2 scenario over the period 2002-2099. Model names and runs as indicated. A trend (bar/rod) is given for every individual CMIP3 A2 run. Units Pa/year or SOI units/year

and Tahiti (101,107 Pa, 101,329 Pa, respectively). However, they equate to 50 and $120 \%$ of the standard deviation in MSLP at these two locations (79 and $71 \mathrm{~Pa}$, respectively), so in this sense the trends are not small. Notice also that the increase at Tahiti tends to be larger than the increase at Darwin. This gives rise to a positive trend in both $\Delta \mathrm{P}$ in 30 out of 34 runs (MMMRM trend $=0.44 \mathrm{~Pa} /$ year) and in the SOI (31 out of $34,+0.04$ SOI units/year approximately).

The results from the A1B runs (Fig. 3a, b) are very similar to those for A2, although the consensus is not as strong and the changes smaller. There is a strong consensus amongst the models for the trend in BoxW to be positive (Fig. 3a), with positive trends in 42 out of 52 runs (MMMRM trend is approximately $0.3 \mathrm{~Pa} /$ year). There is also a consensus for a negative trend in Box $\Delta \mathrm{P}$ ( 40 out of 52 runs, $-0.16 \mathrm{~Pa} /$ year) and in the BoxSOI $(-0.01$ BoxSOI units/year, 38 out of 52). There is again no consensus amongst the models on the sign of the trend in BoxE.

There is also a consensus amongst the model runs for the trend at Darwin to be positive (Fig. 3b, approximately
$0.26 \mathrm{~Pa} /$ year, 39 out of 52 runs) and in MSLP at Tahiti (0.66 Pa/year, 47 out of 52 runs). The increase at Tahiti again tends to be larger than the increase at Darwin. This again gives rise to a positive trend in both $\triangle \mathrm{P}$ (in 44 out of $52,0.4 \mathrm{~Pa} /$ year) and in the SOI (43 out of $52,0.04 \mathrm{SOI}$ units/year).

The modelled 20th century trends are presented in Fig. $4 a, b$ and are generally far weaker than the trends in the 21 st century runs. The corresponding observed trends are also shown as either a green bar if the observed trend is positive or a purple bar if the observed trend is negative. In each case the MMMRM trend (again depicted as a yellow line in each plot) has the same sign as the corresponding observational trend. There is a weak consensus amongst the model runs for BoxW (Fig. 4a) to increase $(0.06 \mathrm{hPa} / y e a r$, 48 out of 71 runs with positive trends), but with no consensus on changes in BoxE. There is no consensus on the sign of either Box $\Delta \mathrm{P}$ (46 out of 71 runs, $-0.08 \mathrm{~Pa} /$ year) or the BoxSOI (approximately -0.012 BoxSOI units/year, 45 out of 71 runs) to decline. While the majority of the integrations exhibit an increase in Darwin MSLP (Fig. 4b) the 


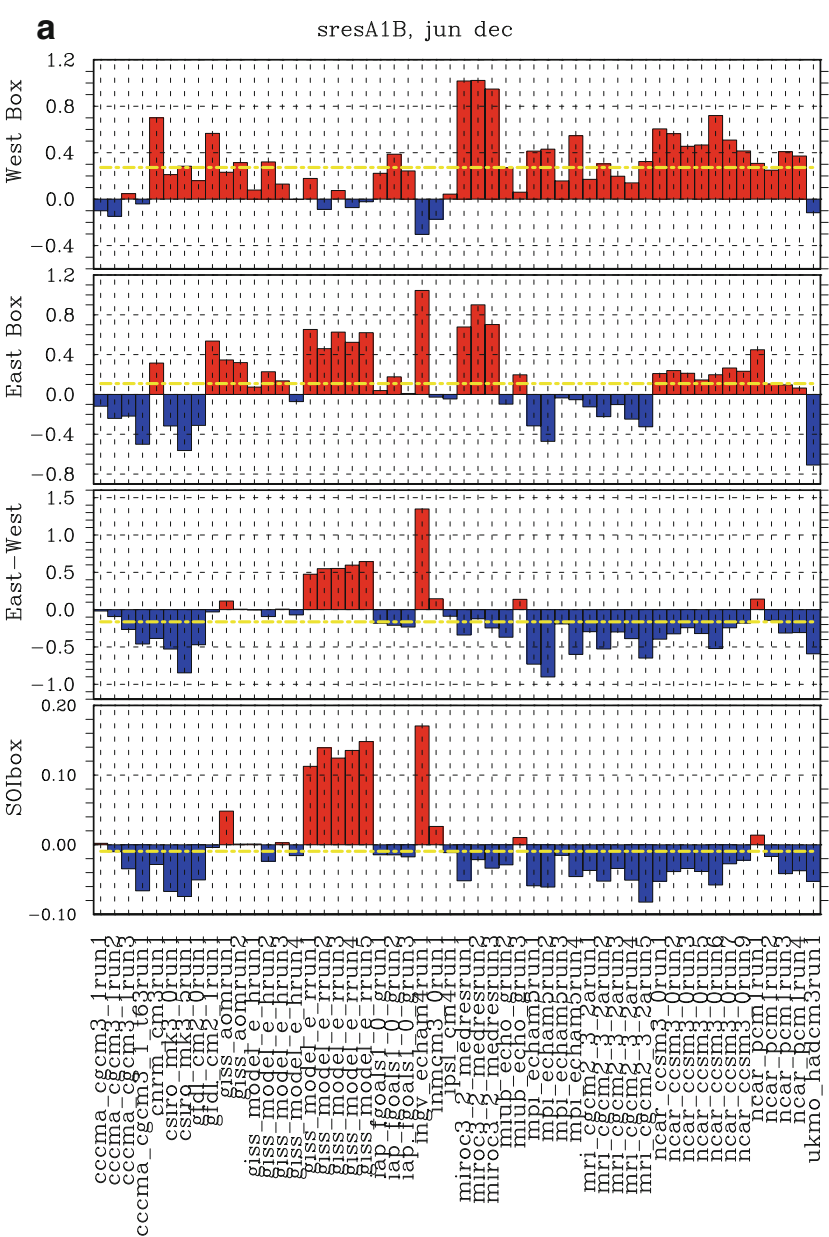

Fig. 3 Modelled 21st century trends in $\mathbf{a} b o x$-based indices and $\mathbf{b}$ the Tahiti-Darwin based indices under the A1B scenario over the period 2004-2099. Note that some models did not have data for 2002-2003

MMMRM trend is small (0.04 Pa/year) and there is no consensus, with only 41 runs out of 71 having a positive trend. There is no consensus amongst the models at Tahiti. The MMMRM SOI trend is negative, but is small $(-0.007$ SOI units/year) and there is no consensus amongst the models. Given the robust signals in the 21st century runs, it appears that the externally forced signal during the 20th century is relatively small and can be easily masked by naturally occurring variability.

A trend for each model run was presented in Figs. 2, 3, 4. Note that some models have more than one ensemble member. Ensemble means (one for each model) for the eight indices, with $\mathrm{A} 2, \mathrm{~A} 1 \mathrm{~B}$ and $20 \mathrm{C}$ forcing were also calculated. The average of all these individual ensemble mean trends was calculated to produce a multi-model ensemble mean (MMEM) trend. The MMEM trends and the degree of consensus on the sign of the trend amongst the individual model ensemble means are presented in Table 3. These results are consistent with Figs. 2, 3, 4: there is a consensus that Darwin, Tahiti, and BoxW MSLP b $\quad$ sresA1B, jun dec
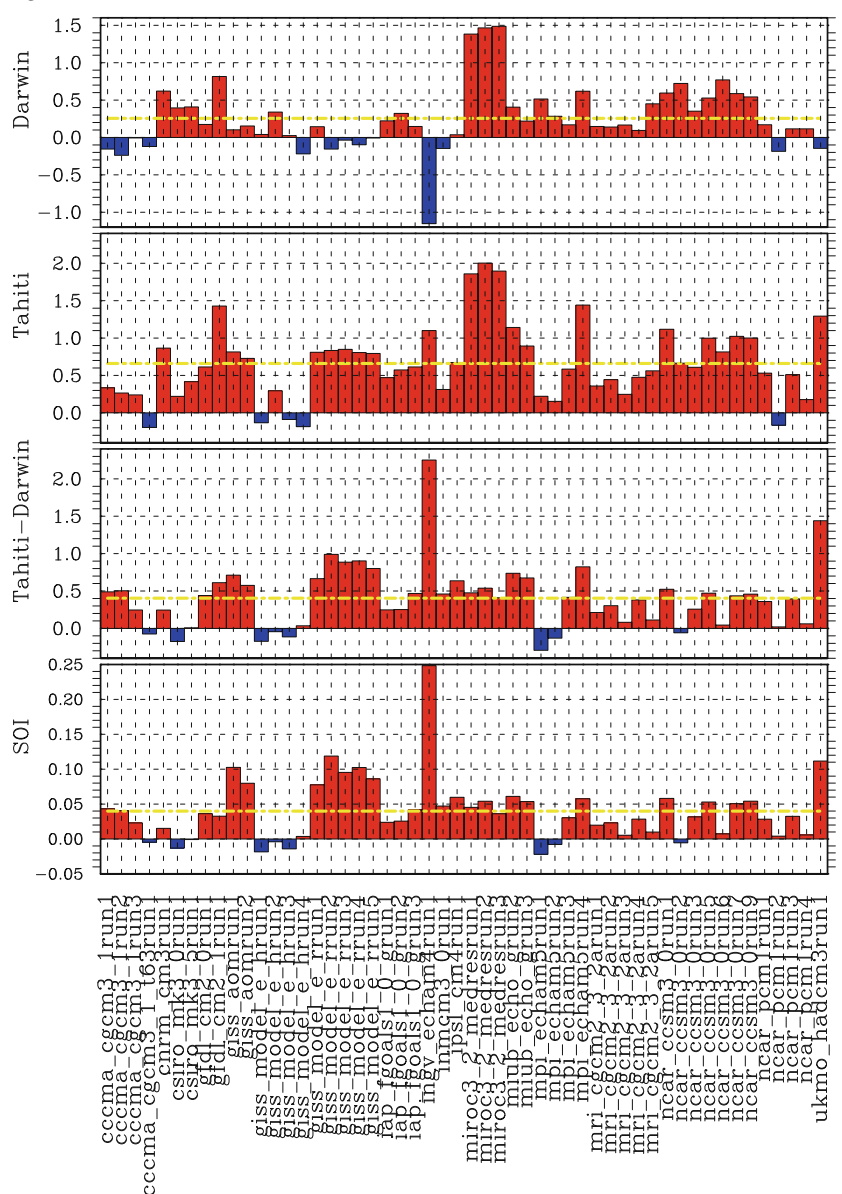

hence the slightly later start date compared with Fig. 2. Units $\mathrm{Pa} / \mathrm{year}$ or SOI units/year

will increase in the 21st century, that Tahiti MSLP will tend to increase more than Darwin MSLP and that the SOI will increase. There is also consensus that $\operatorname{Box} \Delta \mathrm{P}$ and the BoxSOI will trend down. There is no consensus on 21 st century changes in BoxE or on any changes in 20th century trends.

Both the significance of the observed trends and the degree of consensus amongst the models was assessed. The sign of the significant observed trends and the sign of the modelled trends displaying a degree of consensus can be compared in Table 4. In all cases bar one the signs are the same, with MSLP at Darwin and BoxW rising, and with $\Delta \mathrm{P}, \operatorname{Box} \Delta \mathrm{P}$, and the BoxSOI all falling. BoxE the exception. It exhibits a downward trend in the observations, whereas there is no consensus on modelled changes in BoxE.

The relatively small size of the externally forced signal in the 20th century is confirmed in Fig. 5, which shows the evolution of the SOI in the observations and the models. The centred, 30 year running average of the MMEM SOI is 

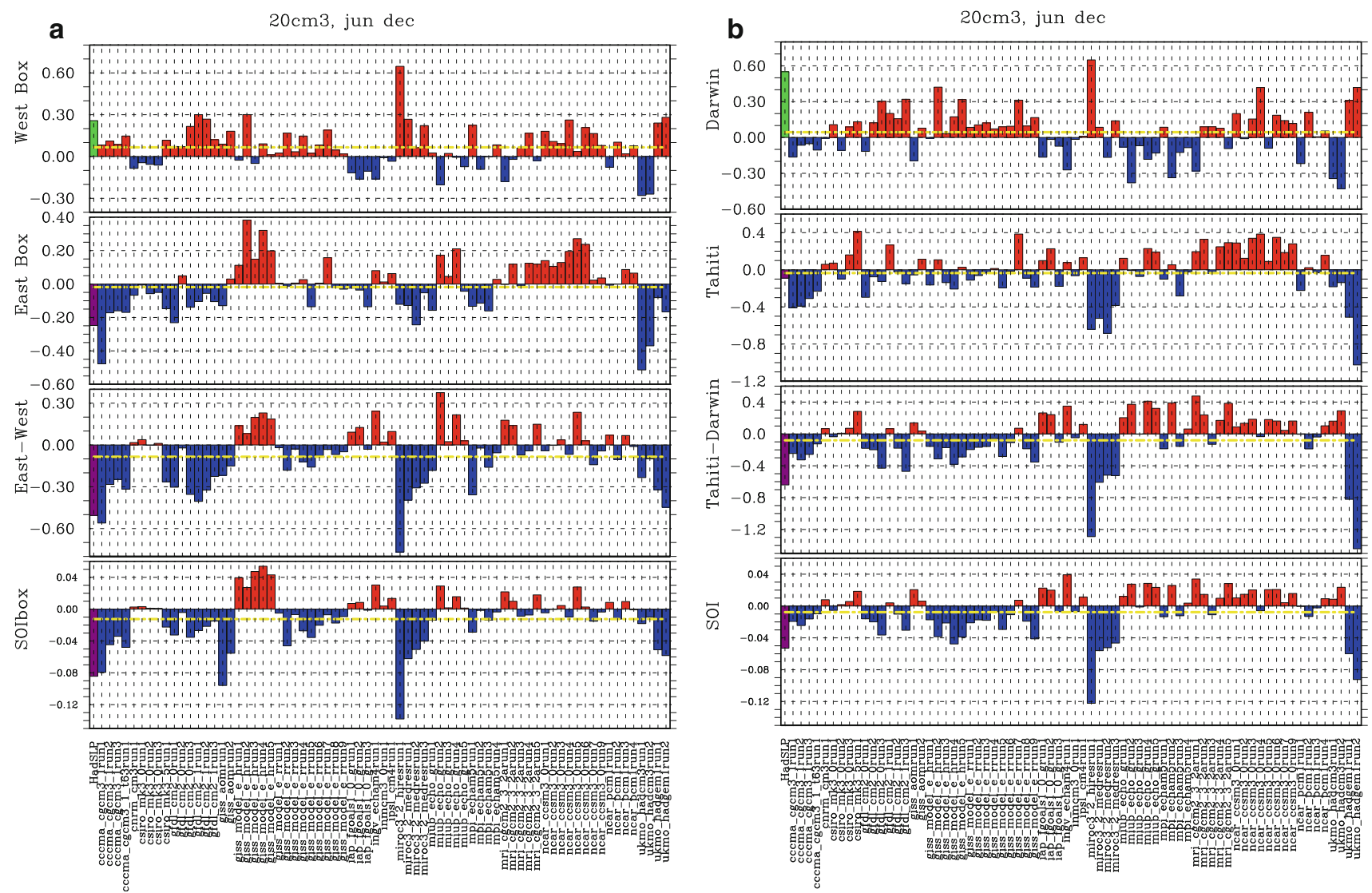

Fig. 4 Modelled 20th century trends in $\mathbf{a}$ box-based indices and $\mathbf{b}$ the Tahiti-Darwin based indices over the period 1901-1998. Units Pa/year or SOI units/year

Table 3 Multi-model ensemble mean (MMEM) trends for A2, A1B and 20th century runs, the number of individual model ensemble mean trends with the same sign as the MMEM trend, and the corresponding percentage

\begin{tabular}{|c|c|c|c|}
\hline INDEX (units) & A2 ${ }_{\text {models })}^{(17}$ & A1B ${ }_{\text {models })}^{(21}$ & $\begin{array}{c}20^{\text {th }} \text { Century } \\
(23 \text { models })\end{array}$ \\
\hline Darwin $(\mathrm{Pa} / \mathrm{yr})$ & $0.34,12,71$ & $0.2,15,71$ & $0.03,12,52$ \\
\hline Tahiti (Pa/yr) & $0.9,17,100$ & $0.7,19,90$ & $-0.08,12,52$ \\
\hline$\Delta \mathbf{P}(\mathrm{Pa} / \mathrm{yr})$ & $0.6,15,88$ & $0.48,18,86$ & $-0.11,11,48$ \\
\hline SOI (SOI units/yr) & $0.046,15,88$ & $0.047,17,81$ & $-0.01,11,48$ \\
\hline BoxW $(\mathrm{Pa} / \mathrm{yr})$ & $0.35,14,82$ & $0.22,16,76$ & $0.07,14,61$ \\
\hline BoxE (Pa/yr) & $-0.03,9,53$ & $0.05,11,52$ & $-0.05,15,65$ \\
\hline $\operatorname{Box} \Delta \mathbf{P}(\mathrm{Pa} / \mathrm{yr})$ & $-0.38,14,82$ & $-0.17,17,81$ & $-0.12,12,52$ \\
\hline $\begin{array}{l}\text { BoxSOI (BoxSOI } \\
\text { units/yr) }\end{array}$ & $-0.042,14,82$ & $-0.01,17,81$ & $-0.02,12,52$ \\
\hline
\end{tabular}

Colours correspond to the degree of consensus in the model runs (45-60\% (no shading, no coloured text), 61-70\% (no shading, blue or red text), $71-80 \%$ (light blue or pink shading), $81-100 \%$ (blue or red shading)). Red/pink shades or text are given for positive trends, blue shades or text for negative trends presented (the red line). The MMEM SOI at time $t$ is equal to the average of all individual model ensemble mean SOI values at time $t$. The 30 year average value of the MMEM SOI provides a CMIP3 model-based estimate of the externally forced signal in the SOI during the 20th and 21st centuries. Two sets of confidence levels are depicted. The pink lines provide an estimate of the $95 \%$ confidence interval for the 30 year running average of the MMEM SOI. The blue lines provide an estimate of the $95 \%$ confidence interval for the 30 year running average of the observed (30 year average) SOI taking both natural variability and the externally forced signal into account. Further details on the confidence levels depicted in Fig. 5 are provided in the caption.

As foreshadowed the externally forced signal in the SOI is small compared with natural variability during the 20th century, but it does emerge around the beginning of the 21 st century. The externally forced signal in the SOI in 2010 , for example, is approximately +0.4 SOI units, with a $95 \%$ confidence interval of $(-0.1,+1.0)$ SOI units. This is the externally forced signal in the SOI in 2010 estimated using the 20th $\mathrm{C}$ and $\mathrm{A} 2$ runs. This figure then rises to +3.6 SOI units late in the $21 \mathrm{st}$ century under the A2 
Table 4 Degree of consensus in the model runs and the sign of the multi-model, multi-run mean (MMMRM, i.e. the average of all model runs) trend in the 20th (20C) and 21st century (A1B, A2) runs is indicated by colours corresponding the degree of consensus in the model runs (45-60\% (white), 61-70\% (no shading, blue or red text), $71-80 \%$ (light blue or pink shading), $81-100 \%$ (blue or red shading))

\begin{tabular}{|l|c|cc|c|cccc|}
\hline & Darwin & Tahiti & $\Delta \mathbf{P}$ & SOI & BoxW & BoxE & $\begin{array}{c}\text { Box } \\
\Delta \mathbf{P}\end{array}$ & $\begin{array}{c}\text { Box } \\
\text { SOI }\end{array}$ \\
\hline Obs & \multicolumn{1}{|c}{} & & & & & & & \\
20C & 58 & 55 & -55 & -55 & 68 & -55 & -65 & -63 \\
A1B & 75 & 90 & 85 & 83 & 81 & 60 & -77 & -73 \\
A2 & 74 & 94 & 88 & 91 & 85 & -50 & -85 & -88 \\
\hline
\end{tabular}

Red/pink shades or text are given for positive trends, blue shades or text for negative trends. Confidence in the observed trends ("Obs") is assessed using the $t$ statistics for the three periods analysed: white if no trends are significant (at $85 \%$ level) or only one is, pale if two are significant at $85 \%$ level only, deep if two or more are significant at 95\% level, intermediate otherwise

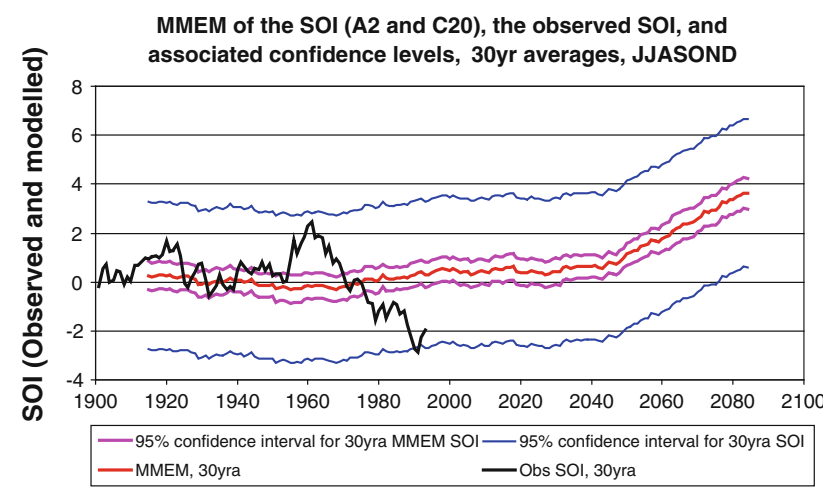

Fig. 5 Evolution of the SOI in the observations and models. The black line shows the 30 year running average value of the observed SOI. The red line is the 30 year running average of the multi-model ensemble mean (MMEM) SOI. The MMEM SOI represents the average of 17 different model averages (one average for each year for each model). The 30 year running average of the MMEM SOI presented provides a CMIP3 model-based estimate of the externally forced signal in the SOI during the 20th and 21st centuries. The pink lines give the $95 \%$ confidence interval for the 30 year running average MMEM, i.e. for the externally forced signal. This is estimated by the interval (MMEM_30 yra $-1.96 \sigma_{\mathrm{E}} / \sqrt{ } 30$, MMEM_30 yra $+1.96 \sigma_{\mathrm{E}} / \sqrt{ } 30$ ), where MMEM_30 yra is the 30 year running average of the MMEM SOI, and $\sigma_{\mathrm{E}}$ is an estimate of the variability in the externally forced signal using the standard deviation of year-to-year changes in the MMEM in running 30 year blocks. The blue lines approximate the $95 \%$ confidence interval for MMEM_30 yra, taking both natural variability and the externally forced signal and its uncertainty into account. This 2 nd interval is estimated using [MMEM_30 yra $-1.96 \sqrt{ }\left\{\left(\sigma_{\mathrm{E}}^{2}+\sigma_{\mathrm{N}}^{2}\right) / 30\right\}, \quad$ MMEM_30 yr$\left.\mathrm{a}+1.96 \sqrt{ }\left\{\left(\sigma_{\mathrm{E}}^{2}+\sigma_{\mathrm{N}}^{2}\right) / 30\right\}\right]$, where $\sigma_{\mathrm{N}}$ is an estimate of natural variability in the SOI using the standard deviation of observed yearto-year changes in the SOI during 1933-1992. Only (17) models with both 20th century and A2 runs are included in the analysis presented in this plot. All variables are based on June-December data

scenario. These figures (i.e. +0.4 and +3.6 SOI units) correspond to +5 and $+40 \%$ of the standard deviation of the SOI. They also correspond to approximately +45 and
$+340 \%$ of the standard deviation of 30 year running averages of the SOI.

Note that ENSO continues to drive strong variability about these new base-level or background values set by external forcing. Thus, the actual value of the SOI in any given year will vary a great deal, often well beyond confidence level for the externally forced signal. This is evident in Fig. 5, which shows that the 30-year running average value of the observed SOI moved well below the relatively narrow (pink) interval associated with signal uncertainty. In fact the 30 year average SOI actually fell below the lower full (blue) confidence level in recent decades, at a time when the externally forced signal was probably positive. This indicates that the recent observed decline in the SOI was driven by unusually large natural variability and not external forcing.

\section{Summary and discussion}

A summary of the trend analysis for all the runs is presented in Tables 3 and 4 . A strong consensus amongst the 21 st century runs is evident:

- MSLP in BoxW increases but there is no consensus about changes in BoxE. This results in a robust reduction in both the $\operatorname{Box} \Delta \mathrm{P}=\mathrm{BoxW}-\mathrm{BoxE}$ and the BoxSOI, consistent with a weakening of the WC.

- MSLP at Darwin and Tahiti both tend to increase. The increase in MSLP at Tahiti tends to exceed the increase at Darwin. This drives a very robust increase in both $\Delta \mathrm{P}=$ Tahiti - Darwin and the SOI.

- Thus the 21st trends in $\Delta \mathrm{P}$ and the Box $\Delta \mathrm{P}$ have the opposite sign as do the trends in the SOI and the BoxSOI.

These changes in the Box $\Delta \mathrm{P}$ and the BoxSOI are consistent with the results of Vecchi et al. (2006) in their examination of 20th century trends. Here we have shown that the trends in Box $\Delta \mathrm{P}$ arise from an increase in west Pacific equatorial MSLP (BoxW) and not from a reduction in MSLP in the eastern equatorial Pacific (BoxE).

The impact of external forcing on the SOI is relatively small during the 20th century, and is easily dominated and masked by relatively large natural variability. In fact the observed decline in the SOI has been driven by a large natural, long-lived, transient shift from a La Niña-dominated period to an El Niño-dominated period that is evident in the observations presented by Power and Smith (2007).

A natural weakening of the WC tends to make both BoxW and Darwin MSLP increase and both Tahiti and BoxE MSLP fall (Table 1). The large-scale MSLP changes driven by the anthropogenic global warming that has already occurred would have reinforced the natural rise at 
Darwin MSLP and BoxW, oppose the natural decline in Tahiti MSLP, but would not affect BoxE. We would therefore expect to see (1) a positive trend in Darwin and BoxW where the natural and anthropogenic signals reinforce each other, (2) a robust trend in BoxE where global warming does not diminish the trend arising from the natural occurrence of El Niño dominance, and (3) a less pronounced or ambiguous trend at Tahiti because the downward trend due to natural variability and the upward trend due to global warming oppose each other. The observational results presented above are consistent with this overall picture.

The projected equatorial changes in the $\mathrm{A} 2$ and $\mathrm{A} 1 \mathrm{~B}$ integrations documented here are consistent with a weakening of the WC in response to global warming. However, this weakening is accompanied by an increase in MSLP over a very large region encircling much of the southern hemisphere (Meehl et al. 2007a) which includes Tahiti. This increase tends to be enhanced at latitudes south of Tahiti, where it can be partially attributed to a meridional (north-south) broadening of the Hadley Circulation (Meehl et al. 2007a; Lu et al. 2007) and a poleward shift of storm tracks (Yin 2005).This anthropogenic increase in MSLP at Tahiti in the 21 st century is presumably moderated to some extent by a smaller magnitude fall in MSLP occurring in response to the anthropogenically forced weakening of the WC.

We have shown that while the SOI is an excellent indicator of observed interannual variability in WC changes as indicated by zonal differences in equatorial MSLP (see Tables 1 and 2, and associated discussion) it is a misleading indicator of changes in the WC linked to global warming in the 21st century. Darwin MSLP alone, on the other hand, might be a better measure of changes in the WC and in the equatorial MSLP gradient, because it reflects changes arising from both natural variability and anthropogenic warming (Figs. 2 and 3) in a consistent fashion. In other words, Darwin MSLP increases if the equatorial MSLP gradient weakens, whether the weakening is due to natural variability or anthropogenic global warming.

The impact of external forcing on the SOI in the historical record was shown to be small compared with naturally occurring interannual variability in the SOI. The externally forced signal in 2010 was estimated to have a magnitude equal to approximately 5\% of the standard deviation of variability in the (June-December) SOI during the 20th century reference period. However, this figure is projected to increase to $45 \%$ by the end of the century under the A2 scenario. Thus, statistical prediction schemes which use the SOI will need to be either modified or replaced by climate model-based prediction schemes in the years ahead, as the global warming signal in the SOI (and the quantity being predicted) becomes larger.

External forcing is already a major contributor to interdecadal variability in the SOI: the externally forced signal in 2010, for example, is equal to $40 \%$ of the standard deviation of 30-year running averages of the SOI. The magnitude of the externally forced anthropogenically driven signal in the SOI is projected to increase to over three times the value of the 20th century reference value of the standard deviation of interdecadal changes in the SOI by the end of the 21 st century under the A2 scenario. While global action will hopefully prevent anthropogenic forcing of this magnitude occurring, it seems inevitable-barring some catastrophic event that fundamentally alters the earth's climate-that global warming will become the primary driver of interdecadal changes in the SOI in coming decades.

Finally note that climate models exhibit deficiencies in their simulations of tropical processes in the Pacific (see e.g. Guilyardi et al. 2009) and they show a range of sensitivities to increased greenhouse gases (Meehl et al. 2007a). It will therefore be very interesting to see if future models also tend to exhibit an increase in the SOI in response to global warming.

Acknowledgments The gridded MSLP data was provided by the UKMO. We wish to thank the CLIVAR WGCM Climate Simulation Panel for devising, initiating and managing the WCRP/CLIVAR/ WGCM CMIP3 experiment, agencies participating in CMIP3, PCMDI in the US for collecting, collating and making CMIP3 output available, and both Aurel Moise and Lawson Hanson for providing ready access to the data here in the Bureau of Meteorology. This research was partially supported by the Australian Climate Change Science Program, which is administered by the Australian Department of Climate Change and Energy Efficiency.

Open Access This article is distributed under the terms of the Creative Commons Attribution Noncommercial License which permits any noncommercial use, distribution, and reproduction in any medium, provided the original author(s) and source are credited.

\section{References}

Aidiku SGK, Stone RC (1995) Using the SOI for improving rainfall prediction and agricultural water managements in Ghana. Agric Water Manag 29:85-100

Allan RJ, Ansell TJ (2006) A new globally complete monthly historical mean sea level pressure data set (HadSLP2): 1850-2004. J Clim 19:5816-5842

Allan RJ, Lindesay J, Parker D (1996) El Niño-Southern Oscillation and climatic variability. CSIRO, Collingwood, p 402

Bouma MJ, Dye C (1997) Cycles of malaria associated with El Niño in Venezuela. J Am Med Assoc 278:1772-1774

Callaghan J, Power SB (2010) Variability and decline in severe landfalling tropical cyclones over eastern Australia since the late 19th century. Clim dyn (submitted) 
Chiew FHS, Piechota TC, Dracup JA, McMahion TA (1998) El Niño and Australian rainfall, streamflow and drought: links and potential for forecasting. J Hydrology 204:138-149

Chu PS, He Y (1994) Long-range prediction of Hawaiian winter rainfall using canonical correlation analysis. Int $\mathrm{J}$ Climatol 14:659-669

Collins M, An SI, Jin FF, Guilyardi E, Power S, Wittenberg A, Ganachaud A, Cai W, Timmermann A, Vecchi G, Lengaigne M, Jochum M (2009) The impact of global warming on the tropical Pacific and El Niño. Nat Geosci (acccepted)

Eltahir EAB (1996) El Niño and the natural variability in the flow of the Nile river. Water Resour Res 32:131-137

Gill AE (1982) Atmosphere-ocean dynamics. International geophysics, Vol 30. Academic Press, New York, 662 pp

Folland CK, Karl TR, Christy JR, Clarke RA, Gruza GV, Jouzel J, Mann ME, Oerlemans J, Salinger MJ, Wang S-W (2001) Observed climate variabiltiy and change. In: Houghton JT et al. (eds) Climate change 2001: the scientific basis. Contributions of WG1 to the Third Assessment Report of the IPCC. Cambridge University Press, Cambridge, UK, p 881

Guilyardi E, Wittenberg A, Fedorov A, Collins M, Wang C, Capotondi A, van Oldenborgh GJ, Stockdale T (2009) Understanding El Niño in ocean-atmosphere general circulation models: progress and challenges. Bull Am Meteorol Soc 90:325-340

Hammer G, Mitchell C, Nicholls N (2000) Applications of seasonal climate forecasts to agricultural and natural systems. Kluwer Academic, Norwell, p 469

Holmgren $M$ et al (2001) El Niño effects on the dynamics of terrestrial ecosystems. Trends Ecol Evol 26:89-94

Kahya E, Dracup JA (1993) US streamflow patterns in relation to the El Niño/Southern Oscillation. Water Resour Res 29:2491-2504

Lehodey P, Bertignac M, Hampton J, Lewis A, Picaut J (1997) El Niño Southern Oscillation and Tuna in the western Pacific. Nature 389:715-717

Linthicum KL, Anyamba A, Tucker CJ, Kelley PW, Myers MF, Peters CJ (1999) Climate and satellite indicators to forecast Rift Valley fever epidemics in Kenya. Science 285:397-400

Lu J, Vecchi GA, Reichler T (2007) Expansion of the Hadley cell under global warming. Geophys Res Lett 34:L06805. doi: 10.1029/2006GL028443

Maelzer D, Hales S, Weinstein P, Zalucki M, Woodward A (1999) El Niño and arboviral disease. Environ Health Perspect 107:817-818

Meehl GA, Covey C, Delworth T, Latif M, McAvaney B, Mitchell JFB, Stouffer RJ, Taylor KE (2007) The WCRP CMIP3 multimodel dataset: a new era in climate change research. Bull Am Meteorol Soc 88:1383-1394

Meehl GA et al (2007a) Global climate projections, in climate change 2007: the physical science basis. In: Solomon S et al (eds) Contribution of Working Group I 4th assessment report of the intergovernmental panel on climate change, Cambridge University Press, New York, pp 747-845

Merendo JA (1995) Variations and change in South American streamflow. Clim Change 31:99-117
Nicholls N (1993) El Niño-Southern Oscillation and vector-borne disease. Lancet 342:1284-1285

Nicholls N (2008) Recent trends in the seasonal and temporal behaviour of the El Niño-Southern Oscillation. Geophys Res Lett 35:L19703. doi:10.1029/2008GL034499

Pascual M, Rodó X, Ellner SP, Colwell R, Bouma MJ (2000) Cholera dynamics and El Niño. Science 289:1766-1769

Philander SG (1990) El Niño, La Niña and the Southern Oscillation. Academic, New York, p 293

Phillips JG, Cane MA, Rosenzweig C (1998) ENSO, seasonal rainfall patterns and simulated maize yield variability in Zimbabwe. Agric For Meteorol 90:39-50

Power SB, Smith IN (2007) Weakening of the Walker circulation and apparent dominance of El Niño both reach record levels, but has ENSO really changed? Geophys Res Lett 34, doi:10.129/2007/ GL30854

Power S, Tseitkin F, Torok S, Lavery B, McAvaney B (1998) Australian temperature, Australian rainfall, and the Southern Oscillation, 1910-1996: coherent variability and recent changes. Aust Meteorol Mag 47:85-101

Power S, Casey T, Folland C, Colman A, Mehta V (1999) Interdecadal modulation of the impact of ENSO on Australia. Clim Dyn 15:234-319

Ropelewski CF, Halpert MS (1989) Precipitation patterns associated with the high index phase of the Southern Oscillation. J Clim 2:268-284

Shukla J, Paolino DA (1983) The Southern Oscillation and long-range forecasting of the summer monsoon rainfall over India. Mon Ea Rev 111:1830-1837

Stone RC, Hammer GL, Marcussen T (1996) Prediction of rainfall probabilities using phases of the SOI. Nature 384:252-255

Swetnam TW, Betancourt JL (1990) Fire-Southern Oscillation relations in the southwestern United States. Science 249:1017-1020

Tanaka HL, Ishizaki N, Kitoh A (2004) Trend and interannual variability of Walker, monsoon and Hadley circulations defined by velocity potential in the upper troposphere. Tellus Ser A $56: 250-269$

Trenberth KE, Hoar TJ (1997) El Niño and climate change. Geophys Res Lett 24:3057-3060

Troup AJ (1965) The Southern Oscillation. Q J R Meteorol Soc 91:490-506

Vecchi GA, Soden BJ, Wittenberg AT, Held IA, Leetma A, Harrison MJ (2006) Weakening of the topical atmospheric circulation due to anthropogenic forcing. Nature 419:73-76

Walker GT (1923) Correlations in seasonal variations of weather VIII. Mem India Meteorol Dept 24:75-131

Walker GT (1924) Correlations in seasonal variations of weather IX. Mem India Meteorol Dept 24:333-345

Ward MN (1998) Diagnosis and short-lead time prediction of summer rainfall in tropical North Africa at interannual and multidecadal timescales. J Clim 11:3167-3191

Yin JH (2005) A consistent poleward shift of the storm tracks in simulations of $21 \mathrm{st}$ century climate. Geophys Res Lett 32:L18701. doi:10.1029/2005GL023684 